\title{
Respuesta judicial a la demanda de celeridad: la flagrancia en la Provincia de Buenos Aires (Argentina)
}

Judicial response to the demand for celerity: flagrancy in the Province of Buenos Aires (Argentina)

Resposta judicial à demanda por celeridade: a flagrância na Província de Buenos Aires (Argentina)

Ezequiel Kostenwein*

\section{RESUMEN}

La propuesta de este trabajo es indagar, de forma exploratoria, Palabras clave: cómo se ha desarrollado el procedimiento de flagrancia en la audiencias, provincia de Buenos Aires tomando como referencias a las retóceleridad, demora, ricas oficiales, la observación de audiencias y los testimonios de los actores judiciales acerca del período de su surgimiento (2005prácticas. 2010). Nuestro principal argumento es que la demora judicial, eje central en la fundamentación del mencionado proceso, ha permitido que las controversias y los reclamos respecto al desempeño de la justicia penal estén centradas en el hacer y no en el saber de los operadores jurídicos. En concreto, si se pone atención a las narrativas provenientes tanto de los debates legislativos como de los documentos de ONG involucradas en el arribo de este procedimiento, lo que parece imponerse es la postura de que los integrantes de la justicia no ignoran las consecuencias de su trabajo o, dicho de otro modo, que ellos saben muy bien lo que hacen, pero, aun así, lo hacen. Esto supone que la prioridad para enfrentar la lentitud no estará puesta en concientizar a los acto-

Doctor en Ciencias Sociales, Universidad Nacional de la Plata, Argentina. Docente de grado y posgrado en las Universidades Nacional de La Plata y Nacional del Litoral (Argentina). Es investigador del CONICET, trabaja la prisión preventiva y la justicia penal como problemas públicos en la Provincia de Buenos Aires y, además, es Coordinador del Área de Sociología de la Administración de la Justicia Penal en el Instituto de Cultura Jurídica (Universidad Nacional de la Plata, Argentina). E-mail: ezequielkostenwein@gmail.com 
res judiciales, sino en lograr que modifiquen sus prácticas, siendo el mismo procedimiento de flagrancia un ejemplo de esto.

\begin{abstract}
This work is proposed with the purpose of exploring how the flagrancy process has developed in the Province of Buenos Aires on the basis of official discourse, the observation of hearings and the testimonies of judicial players regarding the period of emergence (2005-2010). Our main thesis is that judicial delay, which is the backbone of the rationale for such process, has enabled disputes and claims over the performance of criminal justice to be focused on the actions rather than on the knowledge of legal operators, specifically, when attention is paid to the narratives from both legislative debates and documents of NGOs involved in the appearance of this process. What seems to prevail is the position that justice members are not unaware of the consequences of their work or, in other words, that they know very well what they are doing, but yet still carry through. This means that the priority when addressing slowness shall not be given for the purpose of raising awareness among judicial players, but to achieve a change in their practice, and the process of flagrancy is a clear example of this.
\end{abstract}

\section{RESUMO}

A proposta deste trabalho é indagar, de forma exploratória, como se desenvolveu o procedimento de flagrância na província de Buenos Aires tomando como referência retóricas oficiais, observação de audiências e testemunhos dos atores judiciais sobre o período de seu surgimento (2005-2010). Nosso principal argumento é que a demora judicial, eixo central para a fundamentação do mencionado processo, permitiu que as controvérsias e as reclamações relativas ao desempenho da justiça penal se concentrassem no fazer e não no saber dos operadores jurídicos. Em concreto, se prestarmos atenção às narrativas provenientes tanto dos debates legislativos quanto dos documentos de ONGs envolvidas na implementação deste procedimento, o que parece prevalecer é a posição de que os integrantes da justiça não ignoram as consequências de seu trabalho ou, em outras palavras, que sabem muito bem o que estão fazendo, mas, mesmo assim, o fazem. Isto implica que a prioridade para enfrentar a lentidão não estará em conscientizar os atores jurídicos, mas sim em conseguir que modifiquem suas práticas, sendo o próprio procedimento de flagrância um exemplo disto.
Keywords: hearings, acceleration, delay, practices.

Palavras-chave: audiências, celeridade, demora, práticas. 


\section{Introducción. El sublime objeto de la demora judicial}

Hace décadas que los tiempos en la justicia, particularmente en lo penal, es un tema que despierta controversias y exigencias tanto en Argentina como en la provincia de Buenos Aires. El hecho de que tribunales y juzgados parecen no resolver con la diligencia esperada los casos de su competencia se ha transformado en un poderoso argumento a partir del cual respaldan sus críticas distintos actores sociales. En este sentido, la demora judicial aparece en el centro de las discusiones, ya sea porque viola los derechos humanos de los imputados que deben aguardar demasiado tiempo a la espera de un juicio o porque genera impunidad el no resolver las causas penales en los plazos correspondientes que luego prescriben sin llegar a una condena (Ciocchini, 2012). Por lo tanto, la lentitud de la justicia genera fuentes de indignación que, en cierta medida, son difíciles de reconciliar entre sí, debido a que, en un caso, se la critica de punitiva, dado que afecta las garantías de las personas encarceladas, y, en el otro, de benevolente, puesto que contribuye a que las investigaciones se extingan antes de dirimirse (Boltanski \& Chiapello, 2005).

Dicho esto, cabría preguntarse qué dimensión de la demora judicial se pone en juego a la hora de los debates y cuáles son los reclamos que la tienen como protagonista. Recurriendo al planteo de Zizek (2008) sobre ideología, podríamos plantear el interrogante de si el problema medular de la lentitud en la justicia está del lado del saber de los actores judiciales o bien del lado del hacer de estos últimos. Más en concreto, la falta de celeridad de la justicia, ¿ha sido adjudicada a algo que sus integrantes ignoran o a algo que conocen pero que no hacen?

En la Provincia de Buenos Aires, puntualmente, la demora judicial emerge con un claro relieve en los enunciados expuestos alrededor de la reforma del Código Procesal Penal (CPP), la cual comienza a tratarse en 1996 y se consagra en 1998 mediante la Ley No 11922. Por aquellos años, los debates parlamentarios lo reflejaban de manera explícita:

(...) la Justicia no es Justicia si no falla pronto, rápido (...). Y la Justicia no es tal si a ese procesado no le damos un mínimo de garantías, porque hasta que no sea penado o hasta que no sea condenado, es 
inocente. (Diario de sesiones de la Cámara de Senadores de la Provincia de Buenos Aires, 1996, p. 3.2382².

(...) el congestionamiento de causas, la lentitud del trámite en los procesos, y la consecuente dilación en el dictado de las sentencias que resultaban finalmente en (...) una desalentadora sensación de inseguridad e injusticia, instalando en la opinión pública la idea de que la demora en el juzgamiento se traduce en impunidad. (Fundamentos de la Ley 11922, 1996).

Si se analizan estos argumentos provenientes del ámbito legislativo $^{3}$, lo que parece imponerse es la postura de que los actores judiciales no ignoran las consecuencias de su trabajo o, en palabras de Peter Sloterdijk (2003), que "ellos saben muy bien lo que hacen, pero, aun así, lo hacen". La demora judicial es, al menos en lo fundamental, producto de lo que hacen los integrantes de la justicia penal y no tanto de aquello que saben. Más concretamente, dado que ellos saben muy bien lo que hacen, lo que se les debe exigir es que lo hagan más rápido. Esto supone que la prioridad para enfrentar la lentitud no estará puesta en el conocimiento sino en las prácticas de los actores judiciales y el procedimiento de flagrancia parece reflejar este presupuesto.

La propuesta de este trabajo es analizar cómo se ha desarrollado el procedimiento de flagrancia en tres departamentos judiciales de la provincia de Buenos Aires ${ }^{4}$ - Mar del Plata, La Plata y Quilmes_- to-

\footnotetext{
$2 \quad$ Citado en Ciocchini (2013, p. 117)

3 El problema de la demora judicial también se refleja en las crónicas periodísticas de
} la época:

Apuran el debate del nuevo Código.

El nuevo Código Procesal Penal Oral propuesto por el gobierno bonaerense es esencialmente acusatorio y permitirá mayor celeridad e inmediación. Así definió la subsecretaria de Justicia de la provincia de Buenos Aires María del Carmén Falbo el anteproyecto que próximamente será enviado a la Legislatura provincial para su tratamiento.

Principales características.

El gran volumen de causas y la lentitud de los procesos son según la funcionaria disfunciones negativas que se propagan en cadena y resienten la eficacia del sistema. Afirmó que paralelamente se instalan en la opinión pública el descrédito y la sensación de impunidad junto con el agravamiento de la superpoblación carcelaria. (La Nación, 1996).

Recuperado de https://www.lanacion.com.ar/sociedad/las-carceles-bonaerensessiguen-siendo-un-polvorin-nid175059

4 Vale mencionar que la Provincia de Buenos Aires es la más extensa de Argentina, con la mayor cantidad de habitantes, los índices de conflictividad más elevado y el nú- 
mando como referencia las retóricas oficiales de sus impulsores, la observación de 62 audiencias y la realización de 24 entrevistas semiestructuradas a actores judiciales respecto del surgimiento de dicho procedimiento: ocho a jueces de garantías, nueve a defensores oficiales y siete a fiscales. Dichas entrevistas se obtuvieron a partir de un criterio de factibilidad con actores judiciales que conocíamos de investigaciones previas y luego siguiendo un muestreo de bola de nieve debido a los obstáculos propios para acceder a quienes se desempeñan en esta institución.

La primera etapa sobre la que trabajaremos comienza en 2005, año en el que se organiza el plan piloto del procedimiento de flagrancia en el departamento judicial de Mar del Plata, y culmina en 2010, cuando este procedimiento se encuentra funcionando en todo el territorio bonaerense ${ }^{5}$.

\section{El surgimiento de la flagrancia en la Provincia de Buenos Aires}

La justicia penal, analizada en tanto institución, puede ser entendida como un ámbito en el que sus integrantes realizan diversas actividades, acaparando parte de su tiempo e intereses o, más en concreto, como un espacio que les suministra a quienes trabajan allí un mundo propio que se organiza en torno a marcos de experiencias muy específicos (Becker, 2003; Goffman, 2007). Como consecuencia, los actores judiciales incorporan y actualizan cotidianamente estructuras intangibles que favorecen que la realidad de los tribunales les resulte como algo dado (Searle, 1997). Así, una condena o una absolución, redactar un expediente o expresarse oralmente en una audiencia, reclamar $\mathrm{u}$ otorgar una prisión preventiva, y exigir o conceder una excarcelación son todas actividades que realizan sin reparar, caso por caso, acerca de sus respectivos principios o transformaciones. En síntesis, valoran y ponen en práctica dichas resoluciones de acuerdo al papel que les asigna la

mero más alto de personas encarceladas de todo el país.

En una primera etapa, en Zárate-Campana y San Martín (fines de 2006), y en una segunda, en Necochea y Pergamino (julio de 2007) y La Matanza y Mercedes (agosto de 2007). Los departamentos judiciales donde continuó la paulatina materialización del plan han sido Junín, Trenque Lauquen (noviembre de 2007); Morón y Bahía Blanca (mayo de 2008); Quilmes y Dolores (julio de 2008); Azul y San Nicolás (diciembre de 2008); La Plata (febrero de 2009); Lomas de Zamora (marzo de 2009); San Isidro (abril de 2010). 
organización a la que pertenecen. Siguiendo a Luc Boltanski (2009), podemos considerar a la justicia penal como una institución,

[La cual resulta ese ser sin cuerpo] que asume la tarea de decir y de confirmar lo que importa. Dicha operación implica el establecimiento de tipos, tipos que han de quedar fijos y memorizados de un modo u otro (...), y muy a menudo almacenados en forma de definiciones, a fin de hallarse disponibles, en caso de necesidad, para calificar, cuando se dé una situación de incertidumbre, aquellos estados de cosas que son objeto de usos y de interpretaciones ambiguas o contradictorias. Las instituciones han de distinguir, muy particularmente, entre lo que ha de ser respetado y lo que no puede serlo. De este modo viene a recaer sobre las instituciones todas las tareas consistentes en fijar una referencia. (pp. 124-127).

Entendiendo a la justicia penal como institución, esta debe, entre otras cuestiones, distinguir aquello que necesita ser respetado, fijando referencias sobre las sanciones a quienes han trasgredido el derecho penal apoyándose en criterios y procedimientos legales determinados (Garland, 2006). En la Provincia de Buenos Aires (en adelante, PBA), la institución de la justicia penal experimentó un cambio importante en el año 1998 cuando empezó a regir la Ley No 11922, que reemplazó el anterior Código Procesal Penal (en adelante, CPP) e introdujo el sistema acusatorio en reemplazo del inquisitivo ${ }^{6}$.

Esta reforma de 1998 fue considerada estructural y de gran envergadura, lo que llevó a sus promotores a reconocer que el cambio en la letra de la ley no aseguraría la plena puesta en práctica del nuevo sistema acusatorio. Más específicamente, plantearon la necesidad de acompañar la implementación de dichas modificaciones con la realización de nuevas adecuaciones al nuevo modelo procesal y una de

\footnotetext{
$6 \quad$ Vale recordar que para la mayor parte de la doctrina jurídica, el modelo inquisitivo del proceso penal se caracteriza por defender más los intereses de la defensa social, el uso del expediente, la no inmediación entre los actores que intervienen en un proceso penal y la concentración en manos del juez de las funciones de investigar y controlar la investigación. Por el contrario, al modelo acusatorio se lo define a partir de la trascendencia que se les da a las garantías del imputado, de separar las tres funciones - acusar, defender y juzgar, y de exigir un proceso contradictorio, público y oral. De cualquier modo, estos modelos difícilmente pueden encontrarse en estado puro, existiendo principalmente sistemas mixtos (Cafferata Nores, 1992; Levene (h.), 1993).
} 
estas adecuaciones se efectuó en el año 2004 con la Ley No $13183^{7}$ que, entre otras novedades, incluyó el procedimiento en caso de flagrancia. Los objetivos explicitados en los fundamentos de esta ley fueron los siguientes: (a) optimizar las intervenciones estatales del sistema penal bonaerense, otorgándoles mayor eficacia, sin detrimento de las garantías individuales, y (b) simplificar el trámite y acelerar los procesos mediante la mejor coordinación de la actividad de las partes, la concentración de peticiones y la simplificación de las formalidades. En concreto, la Ley No 13183 auspició la aplicación de criterios de oportunidad - como el archivo de actuaciones o la suspensión del juicio a prueba- y de procedimientos simplificados - como el juicio abreviado y el procedimiento en caso de flagrancia mencionado ${ }^{8}$.

Al consultarle a los actores judiciales sobre lo que recuerdan acerca de las razones esgrimidas por los portavoces en cuanto al arribo del procedimiento de flagrancia, estos dos propósitos están presentes:

La gran diferencia que instalaron con flagrancia es lo acotado de los plazos, que son mucho más breves, y que las resoluciones se deben dictar en la audiencia oral. Se pensó para dar una respuesta mucho más rápida (...) Todo esto asociado a que el resto de los recursos se utilizarían para investigar casos más complejos. (Fiscal, Departamento Judicial de Quilmes).

Lo que se buscaba era dar una respuesta inmediata, eso es clarísimo, ¿no? Porque frente a la verificación de una hipótesis delictiva con una persona sindicada, obliga a tomar una decisión pronta e inmediata. La demora judicial era lo primero de lo que se hablaba. Pero el otro argumento, que era que, al sacarle estos casos de sencilla investigación a las fiscalías ordinarias, estas fiscalías iban a investigar más exhaustivamente los hechos más complejos. (Jueza de Garantías, Departamento Judicial de Mar del Plata).

La promesa de flagrancia era la de racionalización: un mecanismo que iba a conciliar celeridad, garantías procesales del imputado, y

Publicada en el Boletín Oficial de la Provincia de Buenos Aires el 16 de abril de 2004.

Con estos criterios de oportunidad y procedimientos simplificados se buscó resolver los conflictos de poca relevancia y de prueba sencilla para, de esa manera, destinar mayores recursos institucionales a las investigaciones más dificultosas como, por ejemplo, el crimen organizado. 
selección de los casos. Es decir, agilizar el proceso, y que eso ayude a que casos con más imputados y más difíciles de resolver cuenten con más recursos. (Defensor, Departamento Judicial de La Plata).

Como podemos observar, tanto la optimización por vía de la selección de casos según su complejidad, así como también la simplificación y aceleración de los procesos fueron asimilados por los propios actores judiciales, señalándolos como pilares que justificaron el advenimiento del procedimiento de flagrancia. Esto supone que la narrativa propuesta por los reformadores logró al menos en cierta medida ofrecer un marco de interpretación y análisis (Goffman, 2007) a los integrantes de la justicia penal, marco mediante el cual la lentitud y la ineficiencia comenzaron a ser visualizados como problemas a enfrentar.

\section{La flagrancia en el Código}

Bajo criterios jurídicos, existe flagrancia cuando el autor de un hecho delictivo es sorprendido (a) en el momento de cometerlo o inmediatamente después, (b) mientras es perseguido por la fuerza pública, el ofendido o el público, (c) con objetos o presenta rastros que hagan presumir que acaba de participar en un delito (art. 154) ${ }^{9}$. Es para este tipo de casos que fue diseñado el procedimiento de flagrancia; en la medida que los delitos sean dolosos y su pena máxima no supere los quince años de prisión o reclusión o, en caso de tratarse de un concurso de delitos, ninguno de ellos exceda dicha cantidad de años (art. 284, bis). Para simplificar el modo en que este proceso se activa, podemos enumerar cinco puntos:

1) Desde el momento en que el fiscal conoce sobre la aprehensión de una persona, cuenta con 48 horas ${ }^{10}$ para declarar si el caso será investigado dentro del procedimiento de flagrancia y, si resultara oportuno, requerir al Juez de Garantías (en adelante, JG) que convierta la aprehensión en detención ${ }^{11}$. Esto último deberá ser notifi-

\footnotetext{
9 Para un enfoque integral de la cuestión, remitimos a la lectura de los artóculos 153, 155 y 156 del CPP.

10 El CPP de la PBA establece que este plazo puede extenderse por medio de una resolución fundada, si bien no especifica por cuánto puede extenderse.

11 Según el artículo 151 del CPP de la PBA,

(...) el Juez librará orden de detención (...) siempre que existan elementos suficientes o indicios vehementes de la comisión de un delito y motivos bastantes para sospechar que ha participado en su comisión. La orden será escrita y fundada,
} 
cado a la defensa inmediatamente y de no existir acuerdo sobre si se trata o no de un delito en flagrancia, se detallarán los motivos de dicha discrepancia. La resolución sobre este desacuerdo puede tomarla exclusivamente el JG, en el plazo de las 48 horas de realizada la notificación (art. 284, ter).

2) De quedar el hecho incluido en el procedimiento de flagrancia, el fiscal tendrá 20 días desde la aprehensión — con una prórroga posible por otros veinte días más- para identificar al imputado y solicitar sus antecedentes e informe ambiental, y efectuar las pericias que se consideren necesarias para concretar la investigación (art. 284, quater) ${ }^{12}$.

3) En el plazo mencionado -20 días, con otros 20 de prórroga-, el fiscal, el imputado y su defensor, podrán requerirle al JG la resolución del proceso sin la necesidad de arribar al juicio ordinario a través de la suspensión de juicio a prueba, el juicio abreviado o el juicio directísimo, según el caso de que se trate.

4) Pasado ese período de tiempo y no habiendo solicitado las partes una resolución alternativa del proceso, el fiscal formulará por escrito en el término de cinco días el pedido de elevación a juicio y, si el imputado estuviese detenido, solicitar la prisión preventiva (art. 284, sexies).

5) Por lo dicho anteriormente, la disminución de los plazos en la etapa de investigación es tangible: en flagrancia, se pasa de un lapso de 10 meses - en el proceso ordinario- a uno de 40 días. A esto cabe agregar que se reducen los tiempos para llegar al juicio. En el trámi-

contendrá los datos personales del imputado u otros que sirvan para identificarlo y el hecho que se le atribuye, Juez y Fiscal que intervienen y será notificada en el momento de ejecutarse inmediatamente después (...) No procederá la detención cuando al hecho imputado le corresponda una pena que no supere, en su término medio, entre el mínimo y el máximo previstos, los tres (3) años de privación de la libertad o tratándose de un concurso de delitos, ninguno de ellos supere dicho monto y cuando de las circunstancias del hecho, y de las características y antecedentes personales del procesado, resulte probable que le pueda corresponder condena de ejecución condicional. Sin embargo, se dispondrá su detención cuando registre una condena anterior que impida una segunda condena condicional o hubiere motivos para presumir que no cumplirá la orden o intentará alterar los rastros del hecho, o se pondrá de acuerdo con terceros o inducirá a falsas declaraciones.

12 En la redacción de la Ley № 13183, el plazo era de 15 días no prorrogables. La Ley № 13260 de diciembre de 2004 estipuló los 20 días prorrogable por otros 20. 
te ordinario, no hay límites fijados de tiempo, mientras que en el de flagrancia existe un máximo de sesenta días ${ }^{13}$. Al decir de Iud y Hazan (2008), "una persona acusada de un delito que fue sorprendida en flagrancia debe ser llevada a juicio en un plazo máximo de 100 días" (p. 231).

El problema fundamental del procedimiento diseñado por la Ley No 13183 que acabamos de describir es que no consolidó innovaciones respecto de cómo debía llevarse adelante el trámite para los casos de flagrancia, el cual se seguía realizando por escrito y utilizando el expediente. En efecto, dicha ley mantenía el formato escrito, imposibilitando el avance de la oralidad - fundamental para el sistema acusatorio-y de las audiencias - espacio en el que la oralidad se materializaría - que la reforma al CPP de la PBA de 1998 había buscado impulsar.

\section{Las intervenciones extrajudiciales}

Con el objetivo de promover tanto la oralidad como las audiencias, en el mes de diciembre de 2004 se realizó un acuerdo entre la Procuración General de la PBA, el Ministerio de Justicia, el Centro de Estudios de Justicia de las Américas (en adelante, CEJA) ${ }^{14}$ y el Instituto de Estudios Comparados en Ciencias Penales y Sociales (en adelante, INECIP) ${ }^{15}$, al que luego se sumó la Suprema Corte de la $\mathrm{PBA}^{16}$. En este convenio se enfatizó la necesidad de apuntalar el sistema acusatorio puesto en marcha en 1998 en la PBA y que se había visto limitado por dificultades

\footnotetext{
13 Este plazo fue estipulado en el art. 17 de la Ley No 13811, posterior a la 13183.

14 El Centro de Estudios de Justicia de las Américas (CEJA) es un organismo creado en 1999 por la Asamblea General de la Organización de los Estados Americanos, cuyas metas principales son las de evaluar y llevar a la práctica cambios en los sistemas de justicia regionales, sumado a la posibilidad de producir documentos e intercambiar experiencias entre los países involucrados. Su sede está en la ciudad de Santiago de Chile. 15 El Instituto de Estudios Comparados en Ciencias Penales y Sociales (INECIP) es una fundación surgida en el año 1989 en Buenos Aires, Argentina, con la intención de contribuir al fortalecimiento del estado de derecho en los países de América Latina y del Caribe. Otros de sus objetivos son los de mejorar los instrumentos legales que ayuden a garantizar el pleno respeto de los derechos fundamentales, construir una perspectiva científica rigurosa y comprometida con los derechos fundamentales de las personas y consolidar una red fluida de intercambio regional a través de la firma de convenios de cooperación e intercambio con distintas organizaciones no gubernamentales.

${ }_{16}$ Disponible en https://www.ohchr.org/Documents/HRBodies/CED/elections/MrHazan.pdf
} 
técnicas y operativas. Más específicamente, INECIP y CEJA e (2006) señalaron los siguientes inconvenientes: (a) La carencia o debilidad de los sistemas de información del poder judicial (en adelante, PJ); (b) Como consecuencia del punto anterior, la imposibilidad de tomar decisiones institucionales estratégicas para una política criminal sensata; (c) La ausencia de una práctica de realización de audiencias orales y públicas en la investigación penal preparatoria (en adelante, IPP), especialmente para el control de las medidas de coerción; (d) La falta de un sistema de gestión que organice dichas audiencias con la presencia de todos los operadores.

Ahora bien, dado que el acuerdo contó con varios participantes, les consultamos a los actores judiciales qué roles habían jugado cada uno de ellos, es decir, qué papel tuvieron las instituciones y agencias que lo habían firmado en el desembarco del plan piloto y posterior consolidación del procedimiento de flagrancia. $\mathrm{Al}$ respecto, nos dijeron lo siguiente:

El procedimiento de flagrancia nace como un acuerdo entre la corte, la procuración, el CEJA e INECIP. La procuración en ese momento, que estaba Falbo, le había puesto mucha energía para que esto funcione, crearon en departamento judicial fiscalías específicas de flagrancia, y en seguida se empezó a trabajar relativamente bien. (Defensora, Departamento Judicial de La Plata).

Yo formé parte del diseño original. El plan piloto surge cuando asume el cargo la procuradora Falbo, que había sido subsecretaria de justicia cuando se sanciona el CPP actual. En ese momento, en 2004, ella vuelve a las fuentes de donde habían salido las ideas centrales del proyecto del CPP que tenía que ver con Alberto Binder y con INECIP, se reúne con él y le dice, “¿qué pasó?, que un CPP en el que habíamos puesto tantas esperanzas salió tan mal?". No el CPP, sino cómo lo implementamos, era horrible. (Fiscal, Departamento Judicial de Quilmes).

El procedimiento se organizó a partir del desembarco de una serie de instituciones, fundamentalmente la procuración que lo motorizó institucionalmente, con apoyo del CEJA y el INECIP que tuvieron una gran presencia en la preparatoria del plan piloto. Y también se seleccionó AJ que fueran promotores hacia adentro de la JP, que 
pudiesen tener cierto liderazgo en el proceso desde adentro, tanto por un compromiso como por el cargo. (Juez de Garantías, Departamento Judicial de Mar del Plata).

Estos testimonios permiten captar una cuestión importante que el procedimiento de flagrancia refleja con claridad: las relaciones y tensiones entre la justicia penal y determinadas agencias extrajudiciales, en particular, con el campo político y las ONG's.

\subsection{Relaciones "oficiosas"}

Siempre es un tema incómodo aludir al vínculo estrecho - aunque excepcionalmente explicitado- que existe en la PBA entre los poderes ejecutivo, legislativo y judicial, principalmente porque forma parte de aquello que permitiría poner en duda la célebre independencia de la justicia (Barrera, 2020; Kostenwein, 2018, 2019). Siguiendo a Bourdieu, aquí parece haber un desplazamiento de lo que se considera oficial, es decir, aquello relacionado al decoro o al pundonor, y que por ello puede afirmarse de manera expresa, pública y dotarse del derecho a la visibilidad hacia lo que se define como "oficioso", lo que representaría los poderes ocultos, escondidos, secretos o inconfesables (Boltanski, 2009, 2016; Bourdieu, 2001, 2007). Por ejemplo, María del Carmen Falbo, a quien ya señalamos como una pieza clave en el impulso de este procedimiento, fue, entre 1995 y marzo de 1998, subsecretaria de justicia bonaerense, siendo luego promovida al cargo de secretaria de esa cartera desde abril de 1998 a diciembre de 1999. A fines del año 1999 asumió como diputada nacional por la Provincia de Buenos Aires, resultando reelecta para ese cargo legislativo en el año 2003 y por el que ocupó la titularidad de la comisión de justicia y participó como integrante de las comisiones de legislación penal, legislación general, de poderes y reglamento, y de derechos humanos y garantías; y en agosto de 2004 juró como procuradora general de la SCJPBA. Así, es factible observar que se trata de una personalidad con una fuerte impronta de gobierno más que una experta técnico-jurídica. En este sentido, se diferencia de la mayoría de los actores que arribaron a cargos importantes dentro del ámbito de la justicia hasta ese momento en el hecho de que no tuvo una carrera judicial tradicional. Esta situación ha sido reconocida por la propia Falbo:

No te olvides que la reforma la inicié, es decir yo asumí acá en agosto del 2004 y tuve que revertir muchísimas cosas, desnaturalizadas 
hasta que yo llegué, porque hubo ministros que boicotearon la reforma, el procurador anterior gracias a Dios se puso la camiseta y empujó porque si no la reforma se hubiera muerto ni bien nos fuimos. Por eso te digo es cuestión de hombros y de política. (Ciocchni, 2013, p. 182).

Por lo tanto, nos hallamos frente a una persona con un claro ceño político, quien además mostró gran compromiso en torno a las reformas de la justicia penal en la PBA desde fines de los años 90. Es importante recordar, también, que la influencia de Falbo se apoya en las características que posee el Ministerio Público de la PBA, al que pertenecen tanto fiscalías como defensorías, y que habilita a la Procuración General a regir la política criminal a través de instrucciones generales. De hecho, la expansión del procedimiento de flagrancia a toda la jurisdicción bonaerense debe ser analizada teniendo en cuenta estos parámetros:

Si bien la introducción de este procedimiento fue realizado a través del "Plan piloto para el fortalecimiento del sistema acusatorio en la Provincia de Buenos Aires" (...), su aplicación en toda la jurisdicción provincial fue posible gracias a la figura de Falbo. Los procedimientos especiales para los casos de flagrancia requerían que los jueces de garantía en la etapa preliminar declarasen (a solicitud del fiscal) que la aprehensión del imputado había sido en flagrancia. Esta primera implementación del "Plan" se realizó en un único departamento judicial y no provocó inconvenientes, porque había un acuerdo de la totalidad de los actores judiciales para llevarlo adelante. Sin embargo, cuando se intentó poner en práctica esta misma experiencia a otros departamentos judiciales hubo mucha resistencia (...) Esta resistencia fue superada a través de la articulación de la ley No 13.943 y las instrucciones generales No 369/08 y 279/09 dictadas por Falbo. Por medio de la resolución No 369/08, Falbo ordenó a los fiscales priorizar la utilización del procedimiento especial para casos de flagrancia. Posteriormente, la ley № 13.943 le quitó a los jueces el poder de decidir si un caso debía ser considerado como flagrante o no (y por lo tanto procesado dentro del procedimiento especial para flagrancia). Este poder de decidir cuándo un caso sería tratado como flagrante fue a parar en los fiscales. (Ciocchni, 2013, pp. 141-142). 
En definitiva, tanto la llegada del plan piloto del procedimiento de flagrancia como su puesta en práctica en toda la provincia necesitan ser evaluadas a partir del vínculo entre la justicia penal y la arena política, siendo Falbo la personificación de dicho nexo. A esto, cabe agregar que la Procuración General, especialmente a partir de la llegada de la propia Falbo, comienza a tener injerencia no solo en la interpretación y aplicación de las normas jurídicas, sino además en la elaboración y ejecución de políticas criminales concretas a partir de instrucciones generales.

\subsection{Los objetivos de capacitar}

El segundo elemento que surge de las expresiones de los actores judiciales es el del rol que asumieron determinadas ONG en el arribo del procedimiento, más en concreto, la mención que hacen los integrantes de la JP del CEJA e INECIP, ambos encargados del apoyo técnico del Convenio de Cooperación para el Reforzamiento del Sistema Acusatorio en la Provincia de Buenos Aires, firmado en diciembre de 2004. En la cuarta cláusula de este convenio se afirma que

(a) Al CEJA le corresponderá prestar asistencia técnica en todas las etapas del programa, tanto en el diseño como en su ejecución, transfiriendo experiencias y tecnologías ya probadas en otros lugares de América Latina. Específicamente, deberá asumir el diseño y aplicación de un plan de capacitación, incluyendo pasantías en instituciones del sistema de justicia chileno para el grupo de personas encargado de diseñar e implementar los programas específicos; la supervisión tanto del diseño como de la ejecución de las actividades concretas que se desarrollen, para lo cual deberá participar en las reuniones de trabajo y talleres que se acuerden, y, finalmente, participar en las actividades de difusión y evaluación del programa. (b) Al INECIP le corresponderá proveer de asistencia técnica en todas las etapas del programa y, particularmente, realizar los relevamientos de información y coordinar las actividades de capacitación, difusión, supervisión y evaluación ${ }^{17}$.

Dos años después de haber suscripto al convenio, CEJA e INECIP realizaron en conjunto un primer documento titulado "Informe eva-

Disponible en https://normas.gba.gob.ar/documentos/V9v64SP0.html 
luativo del plan piloto para el fortalecimiento del sistema acusatorio en Mar del Plata" (2006). Allí, aseveraron que

el objetivo general del proyecto fue el de profundizar el proceso de implementación del sistema acusatorio que había sido introducido en la reforma del año 1998. Con este propósito se pretendió incorporar la metodología de audiencias orales tempranas frente al juez de garantías como mecanismo destinado a fortalecer los valores originales de la reforma. (p. 49).

Además, plantearon la necesidad de ofrecer capacitaciones destinadas a cuestiones de gestión y administración, y a la explicación de la lógica de oralización de la justicia en la etapa de garantías a todos los funcionarios y magistrados del departamento judicial. Conjuntamente, se definieron objetivos puntuales como la agilización del procedimiento en general - especialmente evitando la escrituración-, mejorar la calidad de las respuestas del sistema a través de la oralidad, hacer cumplir las agendas de audiencias de los juzgados de garantías, mejorar los sistemas de información, adelantar las decisiones en las que se hagan acuerdos alternativos al juicio oral, aumentar la utilización de acuerdos como por ejemplo las suspensiones de juicio a prueba y mejorar la comunicación interinstitucional.

Por lo tanto, ya desde el inicio del plan piloto parece haber una tendencia a promover nuevos saberes de los actores judiciales presentados como capacitaciones, pero articulándolas con acciones concretas, definidas en tanto objetivos puntuales. Dicho de otro modo, se considera necesario enseñarles a los integrantes de la justicia penal sobre cuestiones de gestión y administración o sobre la lógica de oralización, pero tan o más importante que eso es el desarrollo de nuevas prácticas judiciales para que, entre otras cuestiones, agilicen el procedimiento penal y mejoren la calidad de las respuestas del sistema a través de la oralidad, los sistemas de información y la comunicación interinstitucional.

\section{El saber, el hacer y el legislar}

Con la intención de profundizar en las percepciones de los operadores jurídicos acerca de si las innovaciones del procedimiento de flagrancia estarían orientadas en primer lugar al saber o al hacer del trabajo en la justicia penal, les consultamos sobre sus puntos de vista al respecto. 
Creo que, al hacer, porque el tema de la demora se daba, por presupuesto. En ese punto no había confrontación. Se decía: "nosotros venimos a implementar esto" y nadie decía que la justicia no era lenta. Había consenso y desde ahí se actuaba. En ese sentido, como institución burocrática, la justicia penal tiene ese reflejo que favorece esa actitud. Y las transformaciones son necesarias motorizarlas con actores internos o externos, pero hay que motorizarlas porque si no la inercia lleva a que no se haga demasiado. (Jueza de Garantías, Departamento Judicial de Quilmes).

Yo creo que es un ida y vuelta. Los juristas estamos acostumbrados a aprender discursos y que los discursos mismos te van a decir qué tenés que hacer. Esto es una falacia porque vos terminás haciendo lo que se hace en la institución, te vas acoplando y te olvidás del deber ser en el camino. El cambio sobre empezar a trabajar sobre prácticas concretas, es decir, a cambiar el hacer, iba a permitir demostrarle a los actores judiciales que, si se ponían las pilas y hacían bien las cosas, iba a funcionar y a hacer un uso eficiente de los recursos. Yo siempre digo que no te enseñan el deber ser sino el debería ser, pero no se puede. Pero, y aunque esto hoy no debería decirse, sí se puede. Y se acaban las excusas. Hay un abogado ya fallecido que decía que en realidad no hay que hacer grandes cambios en los códigos, simplemente había que cambiar los horarios de tribunales porque los jueces que a la mañana eran recontra draconianos, a la tarde eran todos garantistas cuando daban clases en la facultad. Hay que poner los tribunales de tarde, que es cuando los jueces se ponen garantistas. (Fiscal, Departamento Judicial de Mar del Plata).

Lo que resulta interesante, y paradójico hasta cierto punto, es que los actores judiciales tienden a coincidir en que la reforma se ha basado más bien en el "hacer" que en el "saber" de los integrantes de la justicia, con la particularidad de que ellos mismos están en condiciones de saberlo, y también de expresarlo. Tal como lo afirma Lahire (2005), no siempre es sencillo ser consciente de lo que se hace y de lo que se sabe, no obstante, sí resulta más factible este tipo de operaciones cuando aquello que se hace y se sabe, cuenta con nominaciones apoyadas por una disciplina o una organización específicas. Más concretamente,

las prácticas y los saberes se hacen más visibles y declarables en la medida que son claramente sostenidos por instituciones. Cuanto 
más ligados están la práctica y el saber a tiempos y lugares específicos, relativamente autónomos, son más visibles y designables como tales. (pp. 138-139).

Por lo tanto, una de las actividades centrales de los reformadores y promotores del procedimiento de flagrancia en la PBA ha sido la de lograr que los actores judiciales adviertan que se debían cambiar las prácticas que ellos mismos conocían, lo que se llevó adelante a partir de una estructura narrativa que se preocupaba por enfatizar más en cómo se hacían las cosas y no tanto en qué cosas hacían. Esto último, incluso, pudo haber contribuido a generar una ilusión de comunidad o de identidad colectiva en torno a la importancia de diferenciar lo que en ese momento era principal - el hacer, la práctica- respecto de lo que se había vuelto secundario -el saber, el discurso.

Sumado al saber hacer, está el "saber legislar". Con esto queremos señalar que, como consecuencia de los resultados del plan piloto en Mar del Plata, los cuales fueron considerados auspiciosos, se rubricó un nuevo acuerdo mediante el cual impulsar la extensión paulatina de la experiencia para hechos de flagrancia a los restantes departamentos judiciales bonaerenses hasta comprender toda la PBA. Y en diciembre de 2007 se elaboró un protocolo de actuación para los casos declarados en flagrancia ${ }^{18}$ que posteriormente fue sugerido como proyecto ante la legislatura de la PBA y promulgado por medio de la Ley $\mathrm{N}^{\circ} 13811^{19}$. Lo dicho supuso que, a diferencia de lo que tiende a acontecer en el ámbito judicial, la reforma legislativa - que empezó a reglamentar el proceso para los casos de flagrancia- fue el resultado de las modificaciones que originalmente habían iniciado en la práctica los actores judiciales mediante el plan piloto desarrollado en Mar del Plata y que gradualmente se implementó en todo el territorio provincial. Un claro ejemplo de esto lo encontramos en los fundamentos de la Ley No 13811 cuando afirma:

[el objetivo es] la normativización de aquellas prácticas que se han demostrado como más efectivas y que han gozado del mayor con-

18 Este protocolo fue elaborado por miembros del Ministerio de Justicia, de la Procuración General y magistrados y funcionarios judiciales de diferentes departamentos judiciales.

${ }_{19} \quad$ Publicada en el Boletín Oficial de la Provincia de Buenos Aires el 7 de abril de 2008. 
senso de los operadores del sistema en los distintos lugares donde se lleva adelante la experiencia, de modo que su convalidación legislativa resultaría sumamente útil para la extensión y consolidación del Sistema Acusatorio de la Provincia de Buenos Aires. (Fundamentos de la Ley No 13811).

En definitiva, ocurrió que la reglamentación procesal legalizó las prácticas que los operadores jurídicos habían desarrollado anteriormente, volviéndose obligatoria su aplicación para los departamentos judiciales de la PBA en los que ya se hubiese puesto en marcha el "Plan para el fortalecimiento del sistema acusatorio", así como para los que gradualmente se incorporasen al mismo (Ley No 13811, art. 1). Por lo tanto, si bien el plan piloto comienza con el propósito de hacer saber a los actores judiciales para que luego ellos sepan hacer, el desenlace es el contrario: el mismo plan piloto demostró que es el hacer aquello que debe transformarse en una fuente del saber legislativo.

\section{Apología de las audiencias}

Como ya lo señalamos, el arribo del procedimiento de flagrancia en la PBA a partir del plan piloto en el Departamento Judicial de Mar del Plata se consolidó a partir de la puesta en práctica de las audiencias orales para la etapa de investigación. Realizando una breve caracterización del espacio físico donde se desarrollan estas audiencias, se puede señalar que existe un estrado que se ubica al fondo -y en el centro- de la sala, donde está situado el JG, con su secretario, en dirección hacia la entrada; a su izquierda se encuentran sentados tras un escritorio la defensa y el imputado del proceso y a su derecha, detrás de otro escritorio, el agente del Ministerio Público Fiscal (en adelante, MPF); más cerca del ingreso a la sala se hallan algunas hileras de sillas para que puedan sentarse quienes asisten ${ }^{20}$. Otra novedad de este procedimiento es que el registro de lo que se expone se lleva a cabo a través de un sistema digital de audio que graba los planteos de los participantes

$20 \quad$ El inicio de las audiencias está marcado por la introducción que lleva adelante el JG, en la que deja constancia del día y la hora de realización de la misma, y el número de IPP. Luego, se nombran los sujetos presentes en la misma: fiscal, defensor, e imputado, a quien se le consulta por su nombre y apellido, DNI, domicilio, trabajo y conformación del grupo familiar. Esto último es lo que configura su situación de arraigo y que puede llegar a ser importante para decidir sobre el otorgamiento de la PP u otra medida de coerción (Kostenwein, 2016). 
desde que comienza hasta que termina ${ }^{21}$. Por último, cabe mencionar que estas audiencias son multipropósitos (Art. 7, ley 13.811), lo que supone que más allá de que cada una de las tres previstas ${ }^{22}$ tiene estipulada un objetivo específico, es posible proponer en cualquiera de ellas los mecanismos procesales previstos (suspensión de juicio a prueba, juicio abreviado, cese de la PP u otra medida de coerción, etc).

Dicho esto, es importante reflejar que buena parte de la literatura sobre las audiencias de flagrancia en la PBA suele destacar, principalmente, los rasgos beneficiosos de las mismas junto con los del sistema acusatorio, oponiéndolos tanto al expediente como al modelo inquisitivo (Binder, 2012; Hazan, 2009).

Un entorno de mayor calidad [la cursiva nos pertenece] en términos de garantías porque permite al imputado [la cursiva nos pertenece] ver al Juez, escuchar al Fiscal, percibir la calidad de su Defensa y ser oído antes de resolver. También en su favor se cuenta que su situación es resuelta con rapidez y cesa su estado de incertidumbre [la cursiva nos pertenece]. Finalmente, en caso de condena, el quantum [la cursiva nos pertenece] de la pena responde al hecho y no a legitimar el tiempo pasado en prisión preventiva [la cursiva nos pertenece] (...) Dicho con brutalidad, pero en forma realista: si el imputado lleva 10 meses detenido en prisión preventiva, ningún Fiscal va a consensuar una pena menor a ese lapso aún cuando el hecho lo mereciera. En cuanto a la víctima [la cursiva nos pertenece], la audiencia es un lugar donde recibe mejor calidad de información, donde sus intereses son atendidos con mayor celeridad [la cursiva nos pertenece] y donde puede participar en tiempo oportuno de modos alternativos de resolución del conflicto que, probablemente, satisfagan mejor sus expectativas. (Riquert, 2008, p. 3).

En concreto, este tipo de trabajos se posicionan como auténticos promotores de la oralidad, soslayando que las audiencias son un ám-

${ }_{21}^{21}$ Según los partidarios del PF, este tipo de registro supone

Un cambio de paradigma sobre la forma de los actos procesales, que pone en jaque mate a la cultura del expediente judicial [y] refuerza la práctica ligada a la necesidad de resolver en la propia audiencia y sin mediaciones escritas que suelen distorsionar lo acontecido o recortar la realidad. (Tapia, 2012, pp. 10-12).

22 Las tres audiencias posibles son la de control de las condiciones de detención, la de excarcelación y posibles acuerdos, y la de finalización. 
bito en el que también pueden desencadenarse disputas y ahondarse asimetrías. A su vez, afirmaciones benévolas así esbozadas contradicen nuestras propias observaciones de las audiencias en varios aspectos: en primer lugar, es difícil afirmar en términos generales que en las audiencias existe una mayor calidad respecto de las garantías del imputado, entre otras, porque este último suele tener intervenciones menores, que se reducen a contestar sí o no a las preguntas de los actores judiciales. Una segunda cuestión, vinculada a la celeridad con la que se resuelve la instancia procesal del imputado, no debe ser vista como una mejora evidente en relación con el expediente. Con frecuencia, y apoyándose en la rapidez del procedimiento de flagrancia, los operadores jurídicos tienden a confirmar en las audiencias prisiones preventivas precariamente fundamentadas ${ }^{23}$. Tercero, es difícil que se pueda limitar la influencia que tendría para el fiscal el tiempo que un imputado pasó en encierro preventivo respecto al monto de la pena a requerir, a partir del uso de las audiencias: si es cierto que ningún fiscal consensúa una pena menor al lapso que el imputado estuvo detenido en prisión preventiva, aun cuando el hecho lo mereciera, esto ocurre a partir de vínculos y negociaciones en los que igualmente participan defensores y JG — sumada la opinión que pueda ofrecer el imputado. Dicho de otro modo, aquello que el fiscal procure acordar sobre el alcance de la pena puede tener menos que ver con el tiempo que el imputado pasó en PP que con lógicas arraigadas que afectan al conjunto de los integrantes de la justicia penal. Cuarto, y último, acerca del papel de la víctima; lo que advertimos en las audiencias que presenciamos nuestras audiencias es que su participación fue casi nula: solo en un caso, la víctima y el imputado compartieron la sala. Más allá de que no estemos en condiciones de ofrecer una conclusión incontestable sobre el tema, sí podemos señalar que la ausencia de los damnificados en los procesos judiciales es un fenómeno muy extendido que difícilmente lo mitiguen las audiencias de flagrancia.

23 En este sentido, fiscales y JG suelen repetir argumentos del tipo "no será demasiado el tiempo en el que se realizarán las pericias" o "ello en atención al breve plazo procesal que tiene como fecha de culminación un proceso de flagrancia". Esto significa que la celeridad, en determinadas ocasiones, es empleada para validar $-\mathrm{y}$ no para restringir- el uso de la PP (Kostenwein, 2016). 


\subsection{Hablando como un expediente}

Otra de las cuestiones que se proclama como beneficiosa de las audiencias en el procedimiento de flagrancia es la inmediación, en particular cómo esta última habilitaría el uso de un lenguaje sencillo en oposición al vocabulario jurídico, tradicionalmente opaco. Dicho de otro modo, las audiencias ofrecerían una comunicación más directa y sencilla entre actores judiciales, víctimas e imputados a partir de la desinformalización del procedimiento penal (Hazan, 2009). Sin embargo, en una cantidad importante de las audiencias que presencia$\operatorname{mos}^{24}$, tanto la declamada sencillez en las formulaciones como la claridad de los argumentos no estuvieron presentes, advirtiendo que los planteos eran tan alambicados como los que se suelen utilizar en los expedientes escritos. Es así que los actores judiciales parecen "hablar como un expediente":

Juez de Garantías: 17 de noviembre, IPP ..., causa ..., seguida a ... por el delito de tentativa de robo calificado por ser perpetrado por escalamiento y agravado por ser perpetrado con un menor. Sr. Defensor.

Defensora: sí, su señoría [la cursiva nos pertenece], esta defensa va a ratificar el pedido de excarcelación de mi asistido atento la calificación legal de los hechos que se le imputan [la cursiva nos pertenece], si situación procesal encuadran dentro de las reglas del artículo 169 inc. primero, y no teniendo penas anteriores (...) entendemos que sería procedente el beneficio porque no existen a juicio de esta defensa peligros procesales que hagan necesaria la medida cautelar, la que por otro lado aparece como desproporcionada (...) de manera que atento a este contrasentido venimos a solicitar se haga lugar a la excarcelación bajo caución juratoria y demás condiciones que vuestra señoría estime correspondan [la cursiva nos pertenece].

Fiscal: gracias señor juez, el MP se va a oponer a la solicitud de beneficio excarcelatorio habida cuenta de considerar que la medida cautelar solicitada tienen como único objetivo asegurar la comparecencia del imputado al proceso [la cursiva nos pertenece], para

${ }_{24}$ De las audiencias que observamos, en al menos 19 de ellas se utilizaron de manera recurrente expresiones sobrecargadas típicas del lenguaje técnico-jurídico. 
ello el MPF realiza un juicio de valor basado en pautas objetivas [la cursiva nos pertenece] de acuerdo a lo establecido en el artículo 148 y 171 del CPP [...] a ello adunado la situación que cabe destacar [la cursiva nos pertenece] que el procedimiento de flagrancia en un término máximo de cien días contará con una decisión final sobre la situación procesal del imputado. Por ello y debido a que el CP no permite la persecución penal en contumacia [la cursiva nos pertenece] y a los fines de asegurar ese proceso cuya obligación cae en cabeza del MPF es que a tenor de lo informado de sus antecedentes [la cursiva nos pertenece] de lo previsto en el artículo 148 solicito le deniegue la excarcelación en los términos del artículo 171.

Tomando en cuenta el desarrollo de este estilo de audiencias, consideramos necesario revisar el papel que cumplen las fórmulas opacas y la función que le adjudican sus críticos más severos, puesto que se puede caer en reduccionismos y asociarlas únicamente a un formato, el del expediente, y no a la búsqueda de "estar en regla" por parte de los actores judiciales, incluyendo el mantenimiento de algún tipo específico de privilegio de su parte. En palabras de Bourdieu (2007), es posible negarle a la regla la eficacia que le adjudica la dogmática jurídica, sin dejar de tener en cuenta que suele existir "un interés en estar en regla [la cursiva nos pertenece] que puede hallarse en el principio de estrategias que apuntan a ponerse en regla [la cursiva nos pertenece], a poner, como se dice, el derecho de su parte" (p. 174). Al apelar a fórmulas estandarizadas y recurrentes, los operadores pueden buscar poner, además del derecho, el desarrollo mismo de la audiencia de su lado, evidenciando que la opacidad no es un fenómeno circunscripto al expediente escrito, sino

a la imposición de una frontera entre aquellos que están preparados para entrar en el juego y aquellos que, cuando se encuentran allí metidos, quedan excluidos de hecho (...) El desfase entre la visión profana de quien va a convertirse en un justiciable [la cursiva nos pertenece], es decir, un cliente, y la visión especializada del experto, juez, abogado, asesor jurídico, etc., no tiene nada de accidental; dicho desnivel es constitutivo de una relación de poder que funda dos sistemas diferentes de presupuestos, de intenciones expresivas, en una palabra, dos visiones del mundo. Este desfase (...) impone un sistema de exigencias cuyo núcleo es la adopción de 
una postura global, visible particularmente en materia de lenguaje [la cursiva nos pertenece]. (Bourdieu, 2001, pp. 186-187).

En este sentido, podríamos insinuar que ya sea oral o escrito, el tema fundamental es el del lenguaje jurídico a partir del cual se organiza la estructura de las relaciones entre actores judiciales y no judiciales en el interior de los procesos, una estructura desigual que difícilmente se desarraigue por la implementación de las audiencias.

A su vez, esto pone en evidencia el problema de hacer esencial a la oralidad, del mismo modo que lo escriturario, oponiéndolos a partir de categorías demasiado amplias como para que contribuyan a dar cuenta de la complejidad de las prácticas y sus lógicas hacia el interior del trabajo de la justicia penal. Un ejemplo claro al respecto es el de enfrentar dos tipos de culturas, la inquisitorial y la de la legalidad, asociando a una de ellas todos los beneficios, y a la otra todos los perjuicios:

Cuando a un conflicto lo formalizamos bajo la lógica del expediente escrito no identificamos nada del conflicto originario: no se encuentra al agresor, ni a la víctima, ni la comunidad participa; todos quedan convertidos en hojas de papel, en actas redactadas con un lenguaje uniforme y artificial (nadie habla ya en el español forense y antiguo de nuestras actas). En la audiencia todo es distinto (...) Los funcionarios estatales no son una "firma" sino una presencia real y la comunidad (afectada también por el conflicto) tienen la posibilidad de hacerse presente en la sala. Las formas cumplen en esta audiencia una función de pacificación porque no ocultan a los protagonistas, no desplazan los conflictos, solo logran que la violencia sea palabras, argumentaciones, debates, presencia controlada y admitida. De esa manera, a través de la generación de un ámbito de comunicación se logra un lugar de pacificación y tolerancia. (Binder, 2012, pp. 232-233).

Como se puede observar en esta caracterización, predomina un marcado antagonismo entre una cultura inquisitorial y una cultura de la legalidad, adjudicándole —si uno llevara al límite este planteo- la autenticidad a la audiencia y el ardid a los expedientes. De allí que resulte crucial dejar de pensar la audiencia únicamente como el dispositivo que agiliza y controla los tiempos, facilita la eficacia y, en el caso de la flagrancia en la PBA, permite llegar a resoluciones en etapas pre- 
liminares al juicio, sino que para analizarla también como un formato tan controvertido como el expediente.

\section{La carga moral de una audiencia}

Bruno Latour (1990), a partir de aquello que define como sociología de los objetos de la vida cotidiana, hace referencia a una expresión imperativa: "Devuelvan la llave de la habitación en la recepción, por favor" colocada en el hall de un hotel, expresión que sin embargo no logra persuadir a los huéspedes para que lo realicen. Así las cosas,

el encargado podría deslizar la expresión y agregar un llavero tan pesado como para que cada cliente solo piense en llevarlo a recepción solo para deshacerse de él cuanto antes. De allí que lo que el cartelito, el enunciado, la disciplina y la moral reunidas no podían imponer, la bola de hierro colado lo logra (...) En cualquier caso, la orden a la que el cliente obedece no es la del inicio. Ha sido traducida y no transmitida (...) Al transportarlo, lo hemos transformado y traducido. Los clientes ya no devuelven la llave de su habitación, sino que se deshacen de un cachivache engorroso que deforma sus bolsillos. (pp. 104-105).

Si se piensa en las audiencias tempranas a partir de los discursos reformistas, advertimos que se convierten en un formato que tiene la capacidad de desplazar, así como lo hace la bola de hierro para los huéspedes el enunciado de la rapidez; o, dicho más concretamente, dentro del procedimiento de flagrancia, la audiencia impone ciertos plazos expeditivos a los actores judiciales, incluso más allá de las interpretaciones que estos últimos hagan de ellos.

A su vez, si tenemos en cuenta que las audiencias en el procedimiento de flagrancia procuran resolver en un plazo breve casos de investigación sencilla evitando que la causa llegue a juicio oral, aparece nuevamente el interrogante con el que inauguramos este trabajo: para los reformadores y promotores de este proceso, los actores judiciales, ¿son conscientes de que la justicia penal es lenta, y aun así trabajan remisamente? o, por el contrario, ¿no tienen conciencia de su lentitud y por eso se desempeñan de esa manera? El punto aquí es el presupuesto en el que se apoyaron los fundamentos de plan piloto, en el sentido de si los cambios en la justicia penal de la PBA — a partir de julio de 2005- 
estaban orientados a concientizar a los actores judiciales de su lentitud o, en cambio, se daba por descontado que ellos lo sabían y, como consecuencia, el objetivo era modificar sus prácticas dentro de la burocracia judicial. Tomando en cuenta el papel central que asume la celeridad en este período, nos pareció interesante preguntarles a los mismos operadores sobre la valoración que hacían acerca de la rapidez o lentitud de la justicia penal en la que trabajan:

Ahí me sale el corporativismo (...) En la PBA hay mucha carencia y además donde hay mayor conflictividad. A mí me parece que los procesos penales son largos en la PBA, pero los operadores hacen lo que se puede: hay falta de recursos humanos alrededor de una conflictividad creciente. (Defensor, Departamento Judicial de La Plata).

Habría que definir lentitud (...), pero yo diría que por el tiempo útil que se utiliza, y por si los tiempos podrían abreviarse, es extremadamente lenta, extremadamente burocrática en trámite, en pasos. Desde este punto de vista, un sistema de audiencias es muy favorable porque evita trámites, que el expediente vaya y venga, demoras innecesarias. Uno podría decir que hoy tranquilamente que si el sistema de justicia cambiara sus rutinas y sus trámites podría resolver los casos mucho más rápido. Defino la lentitud a partir de lo que se hace y de lo que se podría hacer. (Juez de Garantías, Departamento Judicial de Quilmes).

Previo al procedimiento de flagrancia era muy lenta, excesivamente lenta. Yo ingresé al poder judicial en 1983, y desde ahí empezó a ser más lenta con la densidad poblacional, la complejidad de los problemas sociales, el aumento del delito por distintas causas, no solamente la pobreza, sino la educación: hay más delito en la calle, pero también hay más corrupción, hay más delitos económicos, y eso no es por hambre. Todo esto llevó a que en los últimos 20 o 30 años la situación haya cambiado de una manera terrible. Y a esto se suma que muchos procesos son lentos como tortugas, lo que generó que la opinión pública reclame, lo que despertó a ciertos actores judiciales. (Fiscal, Departamento Judicial de Mar del Plata).

La justicia penal medra en la lentitud. Vos a un juez le das un espacio vacío, a un fiscal le das una fiscalía vacía, y les decía: "empiece 
a trabajar hoy", y se angustian y se desesperan. La única forma en la que saben trabajar los actores judiciales, hablando en términos generales, es con cúmulos de tareas. Porque si tiene una habitación llena de causas, puede elegir cuál de todas agarrar, y ¿de qué depende? De si la víctima es insistente, de si el imputado es un pobre infeliz o un tipo poderoso que me puede complicar la carrera. Eso da un marco de arbitrariedad dado por la sobrecarga de tareas que me permite cuidad mi futuro como funcionario, no me meto con los poderosos, meto muchos giles en cana, me dan bien las estadísticas porque hago muchas sentencias de causas tontas. (Fiscal, Departamento Judicial de Mar del Plata).

Como primera cuestión, surge de estos testimonios que aun por diferentes razones, para los integrantes de la justicia penal, esta última es lenta o, como mínimo, tiene inconvenientes para resolver en tiempo y forma los conflictos que investiga. Un segundo tema es que dicha lentitud se diagnostica de manera diferente, en lo fundamental, a partir de dos grandes perspectivas: como un problema social o como producto de variables organizacionales. Esto puede remitirse a interrogantes tradicionales en las ciencias sociales, los cuales oscilan entre la búsqueda de motivos sobre por qué funciona como funciona la sociedad hasta procurar identificar las maneras en que se estructuran áreas específicas del mundo social (Krause, 2019). En un caso, se hace más hincapié en la conflictividad social, en los pocos recursos que el Estado brinda a una justicia bonaerense atiborrada de trabajo o a la endémica corrupción. Aquí parece ponerse el acento en los factores extrajudiciales que los tribunales posteriormente traducen en efectos penales específicos, como sería la lentitud en la resolución de conflictos (Kostenwein, 2019). La otra posición es la que prioriza a la institución, sus marcos de percepción y de actuación: la rutina, los trámites incesantes, la necesidad de acumular tareas y el aprendizaje de cómo gestionar dicho cúmulo. De allí que sea imprescindible pensar qué lugar ocupa la lentitud dentro de un conjunto de relaciones que suponen estructuras y procesos en la configuración de la organización judicial, junto con el modo en el que esto afecta el comportamiento de los individuos en su interior (Vaughan, 2007).

Desde luego que no se trata de explicaciones excluyentes acerca de la lentitud de la justicia penal, pero sí de diagnósticos que poseen pre- 
supuestos diferentes: para unos el problema central es externo-social, y para otros es interno-institucional. Dicho con palabras de Bernard Lahire (2005), en un caso se le da prioridad a lo sociológico y en el otro a lo autobiográfico, y la postura que parece haberse impuesto a partir del advenimiento del procedimiento de flagrancia es la autobiográfica, aunque quitándole centralidad a los actores judiciales y dándosela a las audiencias, en tanto antídoto para combatir la falta de celeridad. En concreto, la rapidez o lentitud de la justicia penal deja de ser un problema únicamente moral ligado al trabajo de los AJ, para transformarse también en uno socio-técnico:

Después de cincuenta años de conducir coches, los responsables de la seguridad vial se han dado cuenta de que no podían confiar en el sentido moral de los conductores para limitar su velocidad. El cinturón de seguridad es pues la delegación de la moral perdida del conductor. (Latour, 1989, p. 2).

Algo similar a lo ocurrido con los cinturones de seguridad puede haber sucedido con la velocidad y los actores judiciales en el procedimiento de flagrancia. Pasados varios años de la reforma procesal de 1998, sus promotores parecen haber confirmado que no es posible confiar solo en el sentido moral de los integrantes de la justicia para profundizar la agilidad de las investigaciones penales y son las audiencias las que se volvieron esa delegación de la moral perdida por parte de los mismos operadores jurídicos.

\section{Conclusión}

Con este trabajo intentamos analizar el problema de la demora judicial a partir del surgimiento del procedimiento de flagrancia en la PBA. Para ello, comenzamos señalando el lugar central que los tiempos de la justicia penal han ido adquiriendo en las últimas décadas, o, dicho de otro modo, que la dificultad de los tribunales para dirimir en plazos razonables los casos en los que interviene se ha erigido como un eficaz argumento mediante el cual respaldan sus críticas diversos actores sociales. Teniendo en cuenta la situación tanto a nivel nacional como de la PBA, surgió la pregunta acerca de si el problema central de la proclamada dilación en la justicia penal está asociado al saber o al hacer de los actores judiciales y sugerimos que, si tomamos en cuenta los planteos derivados del ámbito legislativo, lo que pareció consolidarse es la 
tesitura de que los operadores jurídicos no desconocen los efectos de su trabajo, es decir, que ellos saben muy bien lo que hacen, pero, aun así, lo hacen.

A partir de allí, indagamos sobre el momento en el que la flagrancia aparece en la PBA junto con los criterios con los cuales se la regula en el CPP. En abril de 2004, la Ley No 13183 trajo el procedimiento de flagrancia con el que se trató de impulsar la utilización de criterios de oportunidad - como el archivo de actuaciones o la suspensión del juicio a prueba- y de procedimientos abreviados - como el juicio abreviado y el procedimiento de flagrancia mencionados; y los mismos actores judiciales asimilaron tanto la optimización por vía de la selección de casos según su complejidad, así como la simplificación y aceleración de los procesos, considerándolos pilares que justificaron el advenimiento de la flagrancia. Lo dicho significa que la retórica propuesta por los reformadores consiguió, en ciertos aspectos, brindar un marco de interpretación y análisis a los integrantes de la justicia penal mediante el cual la demora y la ineficacia empezaron a ser vistos como dificultades a enfrentar. Sin embargo, el procedimiento propuesto por la Ley No 13183 mantuvo la realización de los trámites a través del expediente, todo lo cual impidió el desarrollo tanto de la oralidad como de las audiencias.

En diciembre del 2004 se llevó a adelante un convenio entre la Procuración General de la PBA, el Ministerio de Justicia, el Centro de Estudios de Justicia de las Américas (en adelante, CEJA), el Instituto de Estudios Comparados en Ciencias Penales y Sociales (en adelante, INECIP), y la Suprema Corte de la PBA. Allí se destacó la importancia de afianzar el sistema acusatorio aprobado en 1998 en la PBA y que se había visto obstaculizado por inconvenientes técnicos y operativos.

Al consultarle a los actores judiciales sobre la influencia de aquellas intervenciones extrajudiciales, surgieron dos elementos centrales: el campo político y las dos ONG que participaron en el arribo del plan piloto. Por lo que si seguimos sus testimonios, resulta imprescindible analizar las relaciones entre la justicia penal y la arena política, habiéndose transformado la procuradora María del Carmen Falbo en la encarnación de dicho vínculo. Sin ir más lejos, durante su gestión la Procuración General comienza a tener mayor influencia, no solo en interpretar y aplicar las normas jurídicas sino también en la elaboración 
y ejecución de políticas criminales específicas. Sobre el rol del CEJA y el INECIP, los operadores jurídicos coincidieron en que si bien ofrecían capacitaciones para generar nuevos saberes, tanto o más significativos eran los objetivos asociados a acciones concretas hacia el interior de la justicia penal.

En este sentido, los propios actores judiciales consideraron las innovaciones del procedimiento de flagrancia más vinculadas a las prácticas que a la concientización del trabajo en la justicia penal, siendo sugestivo que ellos mismos estuviesen en condiciones de saberlo y, además, de enunciarlo. A esto cabe agregar que el saber hacer se enlazó con el saber legislar, puesto que la regulación procesal refrendó las prácticas que los integrantes de la justicia habían desplegado a partir del plan piloto, todo lo cual volvió obligatoria su aplicación en los departamentos judiciales bonaerenses. Por consiguiente, más allá de que el plan comenzó con el objetivo de hacer saber a los actores judiciales para que luego ellos sepan hacer, las consecuencias fueron otras: el hacer del que partió el mencionado plan piloto se volvió una fuente del saber legislativo.

Otro tema significativo que abordamos es el de las audiencias, sugiriendo que gran parte de la literatura sobre estas últimas resalta sus elementos favorables, no tomando en cuenta que allí también pueden desencadenarse controversias y coacciones. Además, este tipo de aseveraciones poco se relacionan con nuestras observaciones. Una primera cuestión tiene que ver con que los imputados gozarían en las audiencias de "mayor calidad" respecto de sus garantías, lo cual es discutible dado que, por lo que vimos, ellos suelen tener participaciones menores, limitándose a decir sí o no a las preguntas de los operadores jurídicos. En segundo lugar, la velocidad con la que se dirimen las situaciones procesales de los imputados suele perjudicarlos: en muchos casos, con el argumento de la celeridad del procedimiento de flagrancia, los actores judiciales confirman, en lugar de denegar, prisiones preventivas débilmente justificadas. Un tercer elemento tiene que ver con la supuesta incidencia positiva de las audiencias a la hora de que el fiscal tome en cuenta el tiempo que un imputado estuvo en prisión preventiva para solicitar el monto de la pena. Como dijimos, esto se vincula más con prácticas habituales en el seno de la justicia penal que con la oralidad. Por último, advertimos que el papel de las víctimas ha 
sido pasivo, dado que, por lo general, ni siquiera asisten a las audiencias.

Mencionamos también a la inmediación, ya que esta última suele asociarse con las audiencias en el sentido que facilitaría el uso de expresiones simples en oposición al vocabulario jurídico habitualmente opaco. No obstante, nosotros vimos cómo los actores judiciales terminan hablando como un expediente, reproduciendo la falta de claridad en sus formulaciones. Por eso, sugerimos que un tema fundamental es el del lenguaje jurídico, mediante el cual se configuran las relaciones entre operadores del derecho y aquellos que no lo son, una configuración asimétrica que difícilmente se neutralice por la mera utilización de las audiencias.

Luego, y teniendo en cuenta la centralidad del problema de la demora judicial, les consultamos a los propios integrantes de la justicia penal si consideran lenta la institución en la que trabajan, respecto de lo cual surgió, por diferentes razones, cierto consenso: es lenta o al menos tiene dificultades para solucionar en tiempo y forma las causas en las que interviene. A esto se le añade que la lentitud es pensada por los actores judiciales a partir de dos grandes criterios: como un problema que deriva de variables extrajudiciales o como el resultado de factores organizacionales. Aquí se diferencian aquellos que hacen un mayor hincapié en cuestiones sociales - conflictividad social, pocos recursos de la justicia o corrupción endémica - respecto de quienes enfatizan en componentes institucionales - la rutina, los trámites incesantes, la necesidad de acumular tareas. Por último, la tesitura que se consolidó con el procedimiento de flagrancia es la particularidad de que aquellas que obtiene mayor protagonismo son las audiencias, en detrimento de los operadores jurídicos. Esto supone que, al menos en cierta medida, los reformadores han dejado de confiar exclusivamente en los criterios morales de los integrantes de la justicia para consolidar la celeridad de las investigaciones penales, siendo las audiencias las que se transformaron en esa delegación de la moral perdida por parte de dichos integrantes.

En definitiva, buscamos con este aporte ayudar a pensar a la justicia penal como una institución que despierta controversias y exigencias, especialmente por el tema del tiempo empleado para realizar sus labores. El hecho de que tribunales y juzgados no resuelvan con la dili- 
gencia esperada los casos de su competencia se ha vuelto en un enérgico argumento a partir del cual respaldan sus críticas distintos actores sociales. Todo ello exige que se deba seguir avanzando en investigaciones que profundicen los cambios y las continuidades que la exigencia de celeridad provoca en la administración de justicia.

\section{Referencias}

Barrera, L. (2020). Independencia y autonomía. Jueces, fiscales y su cohabitabilidad en el espacio. En E. Kostenwein (Comp.), La condición judicial. Dimensiones sociales de la justicia penal. Buenos Aires: Ad-Hoc.

Becker, H. (2003). The politics of representation: Goffman and total institutions. Symbolic Interaction, 26(4), 659-669.

Binder, A. (2012). La implementación de la nueva justicia penal adversarial. Buenos Aires: Ad-Hoc.

Boltanski, L. (2009). De la critique. Paris: Gallimard.

Boltanski, L. (2016). Enigmas y complots. Una investigación sobre las investigaciones. Buenos Aires: Fondo de Cultura Económica.

Boltanski, L. \& Chiapello, E. (2005). The new spirit of capitalism. Londres: Verso.

Bourdieu, P. (2001). Poder, derecho y clases sociales. Bilbao: Descleé de Brouwer.

Bourdieu, P. (2007). El sentido práctico. Buenos Aires: Siglo XXI.

Cafferata Nores, J. (1992). Medidas de coerción en el nuevo Código Procesal Penal de la Nación. Buenos Aires: Depalma.

Centro de Estudios de Justicia de las Américas. (2017). Desafíos de la reforma procesal penal en Chile: Análisis retrospectivo a más de una década. Santiago de Chile: Centro de Estudios de Justicia de las Américas.

Ciocchini, P. (2012). Domando a la bestia. Las reformas en la justicia penal bonaerense para eliminar la demora judicial. Derecho y Ciencias Sociales, (7), 202-223.

Ciocchini, P. (2013). Tiempo de justicia. (Tesis doctoral). Universidad del País Vasco, Bilbao.

Fundamentos de la Ley 11922 (1996). Código Procesal Penal de Buenos Aires. Recuperado de https://www.argentina.gob.ar/ 
normativa/provincial/ley-11922-123456789-0abc-defg-2291100 bvorpyel

Garland, D. (2006). Castigo y sociedad moderna. México D.F.: Siglo XXI.

Goffman, E. (2007). Internados. Ensayo sobre la situación social de los enfermos mentales. Buenos Aires: Amorrortu.

Hazan, L. (2009). La introducción de audiencias preliminares como variable para la humanización del proceso penal. Santiago de Chile: Centro de Estudios de Justicia de las Américas.

Hazan, L. \& Iud, A. (2008). Informe de evaluación del proceso de fortalecimiento del sistema acusatorio en la Provincia de Buenos Aires. En AA.VV. (Eds.), Primer encuentro nacional Redex Argentina (pp. 161-235). Córdoba: Advocatus.

Instituto de Estudios Comparados en Ciencias Penales y Sociales \& Centro de Estudios de Justicia de las Américas. (2006). Informe evaluativo del plan piloto para la profundización del sistema acusatorio en Mar del Plata. Sistemas Judiciales, (11), 48-67.

Kostenwein, E. (2016). La cuestión cautelar. Buenos Aires: Ediar.

Kostenwein, E. (2018). Sociología de la justicia penal. Precisiones teóricas y distinciones prácticas. Delito y Sociedad, 2(46), 33-72.

Kostenwein, E. (2019). Cuando los poderes se encuentran, los actores confrontan. Cadernos de Dereito Actual, (11), 102-123.

Krause, M. (2019). El "campo" como variable conceptual: Los patrones intermedios. En C. Benzecry (Comp.), La teoría social, aho$r a$. Buenos Aires: Siglo XXI.

Lahire, B. (2005). L'esprit sociologique. Paris: La Découverte.

Latour, B. (1989). The moral dilemmas of a safety-belt. [Traducción inédita]. Recuperado de https://courses.ischool.berkeley. edu/i290-tpl/s11/w/images/6/69/The_Moral_Dilemmas_ of_a_Safety-belt.pdf

Latour, B. (1990). Technology is society made durable. [Monografía]. The Sociological Review, 38(1), 103-131.

Levene (h.), R. (1993). Manual de Derecho Procesal Penal. (Tomo I). Buenos Aires: Depalma.

Riquert, M. (2008). Oralidad y proceso de flagrancia. Disertación presentada en las Jornadas Nacionales 10 años de Vigencia del Sistema Acusatorio en la Provincia de Buenos Aires. La Plata, Buenos Aires, Argentina. 
Searle, J. (1997). La construcción de la realidad social. Barcelona: Paidós.

Sloterdijk, P. (2003). Crítica de la razón cínica. Madrid: Siruela.

Tapia, J. F. (2012). La introducción de audiencias orales en la etapa de investigación. Revista Pensamiento Penal.

Vaughan, D. (2016). Criminología y la sociología de las organizaciones. Analogía, organización social comparativa y teoría general. Delito y Sociedad, 2(24), 7-24. https://doi.org/10.14409/ dys.v2i24.5307

Zizek, S. (2008). The sublime object of ideology. Londres: Verso. 